\title{
Gravimetric investigation of passivation of compact samples made of nickel pyrophoric nanopowders
}

\author{
M. I. Alymov ${ }^{\dagger}$, B. S. Seplyarskii, S. G. Vadchenko, R. A. Kochetkov, V. A. Zelensky, \\ N. M. Rubtsov, A. S. Shchukin, I. D. Kovalev, N. I. Abzalov
}

†alymov@ism.ac.ru

Merzhanov Institute of Structural Macrokinetics and Materials Science, RAS (ISMAN), Chernogolovka, 142432, Russia

Pyrophoric nickel nanopowders obtained by a chemical-metallurgical method were used in investigations. The average nanoparticle size was $67 \mathrm{~nm}$. Compact samples with diameters of 5, 7 and $10 \mathrm{~mm}$ of different densities were made of nonpassivated nickel nanopowder in a glove box in argon atmosphere. In preliminary experiments, in which closed weighing bottles with samples made of nickel pyrophoric nanopowder after extraction from the box and until extraction of samples from the weighing bottles were in an argon atmosphere, the optimal value of the relative density 0.2 of samples was determined, at which they maintained pyrophoric properties, since they self-ignition occurred at heating to $\sim 550-600^{\circ} \mathrm{C}$. Then, for the samples with the densities $<0.2$, the time spent with the closed weighing-bottle in the air as well as the relative weight gain of the samples sufficient for their passivation were determined. The amount of adsorbed monoatomic oxygen layers and the active surface fraction of compact nickel pyrophoric nanopowder samples were calculated based on the obtained relative weight gain information and literature data. It was established that during the exposure of the weighing boxes to the air the passivation of the samples with the preservation of their high chemical activity occurred, since when the oxidation reaction was initiated by a high-temperature source, a combustion wave propagated within the sample with the velocity about $0.3 \mathrm{~mm} / \mathrm{s}$. Analysis of the fracture of passivated samples showed no sintering of nickel nanoparticles; EDA showed an almost uniform distribution of oxygen over the cross section of all passivated samples, which makes it possible to conclude that passivation has superficial nature.

Keywords: nickel pyrophoric nanopowder, compact sample, argon, passivation, relative weight gain.

УДК: 544.452

\section{Гравиметрическое исследование пассивации компактных образцов из пирофорных нанопорошков никеля}

Алымов М.И. ${ }^{\dagger}$ Сеплярский Б. С., Вадченко С. Г., Кочетков Р. А., Зеленский В.А., Рубцов Н. М., Щукин А. С., Ковалев И. Д., Абзалов Н.И.

Институт структурной макрокинетики и проблем материаловедения им. А. Г. Мержанова РАН (ИСМАН), Черноголовка, 142432, Россия

Для исследования применялись пирофорные нанопорошки никеля, полученные химико-металлургическим методом. Средний размер наночастиц составлял 67 нм. Из непассивированного нанопорошка никеля в перчаточном боксе в атмосфере аргона изготовлялись компактные образцы диаметрами 5, 7 и 10 мм различной плотности. В ходе предварительных экспериментов, в которых закрытые бюксы с образцами из пирофорного нанопорошка никеля после извлечения из бокса вплоть до извлечения образцов из бюксов, находились в атмосфере аргона, было определено оптимальное значение относительной плотности образцов 0.2, при которой они гарантировано сохраняют пирофорные свойства, поскольку происходило их самовоспламенение с разогревом до $550-600^{\circ} \mathrm{C}$. Затем для образцов с плотностями не выше 0.2 были определены время нахождения закрытого бюкса на воздухе и относительный привес образцов, достаточные для их пассивации. На основании полученной информации об относительном привесе и литературных данных было рассчитано количество адсорбируемых моноатомных слоев 
кислорода и доля активной поверхности компактных образцов из пирофорного нанопорошка никеля. Установлено, что в процессе нахождения бюксов с образцами на воздухе произошла именно пассивация образцов с сохранением их высокой химической активности, так как при инициировании реакции окисления высокотемпературным источником по образцу запускалась волна горения со скоростью порядка $0.3 \mathrm{~mm} / \mathrm{c}$. Анализ излома пассивированных образцов показал отсутствие спекания наночастиц никеля, а ЭДА показал практически равномерное распределение кислорода по сечению всех пассивированных образцов, что позволяет сделать вывод о том, что пассивация носит объемный характер.

Ключевые слова: пирофорный нанопорошок никеля, компактный образец, аргон, пассивация, относительный привес.

\section{1. Введение}

Пирофорные нанопорошки металлов способны самовоспламеняться при контакте с воздухом из-за высокой химической активности и большой удельной поверхности [1-4]. Для того чтобы сделать процесс дальнейшей переработки нанопорошков в изделия безопасным, их пассивируют [3 - 7]. Пассивация заключается в создании тонкой защитной пленки на поверхности наночастиц, которая препятствует их самовозгоранию. Обычно пассивация продолжается десятки часов, что является ограничивающим фактором для производства и использования нанопорошков. Процессы пассивации нанопорошков железа и никеля исследовались в работах [8-10]. Показана применимость теоретических подходов классической макроскопической теории теплового взрыва [11] для объяснения явлений воспламенения в макроскопических объектах, состоящих из наночастиц железа и никеля.

Однако очевидно, что существуют ситуации, когда проведение пассивации нанопорошка технически невозможно или нежелательно, хотя технические операции с нанопорошком необходимо осуществить. Поэтому актуальной задачей является разработка новых методов получения компактных изделий из нанопорошков, позволяющих обеспечивать требуемый уровень пожаровзрывобезопасности как при переработке нанопорошков, так и изделий из них.

Литературные данные о закономерностях самовоспламенения и саморазогрева компактированных образцов из непассивированных нанопорошков довольно ограничены. Так в работах $[12,13]$ по исследованию зажигания наносистем с размерами частиц реагентов в диапазоне 40-80 нм показано, что температуры и энергии зажигания могут быть значительно ниже, чем в смесях микропорошков (1-100 мкм), например, для системы $\mathrm{Ni}-\mathrm{Al}$ из наночастиц это значение составляло всего 17.4 кДж/моль, а для микронных частиц - 162.5 кДж/моль.

В [14] исследованы особенности распространения пламени по таблеткам из смесей нанопорошков $\mathrm{Al} / \mathrm{CuO}$ (так называемые нанотермиты) в зависимости от плотности при лазерном инициировании горения. Аналогичные измерения, описанные в монографии [15], были проведены для образцов из нанопорошков $\mathrm{Al} / \mathrm{MoO}_{3}$ и полученные для этого нанотермита результаты качественно те же.

Цель работы: с помощью гравиметрического метода определить необходимые условия пассивации компактных образцов различного диаметра, спрессованных из пирофорных нанопорошков никеля.

\section{2. Экспериментальная часть}

Нанопорошок никеля получали следующим образом. Предварительно синтезировали формиат никеля в реакции гидроксида никеля с муравьиной кислотой. Синтез гидроксида никеля осуществляли при щелочной обработке сульфата никеля, осаждении и сушке полученного гидроксида. Формиат никеля начинает диспропорционировать при температуре около $210^{\circ} \mathrm{C}$, при этом образуется нанопорошок никеля и выделяется газовая смесь, состоящая из углекислого газа, водорода и паров воды [16]. Реактор, описанный в [10] с насыпкой порошка формиата никеля толщиной 4 мм (15 г) помещали в печь в кварцевой лодочке и выдерживали в печи 50 мин при температуре $209^{\circ} \mathrm{C}$ в потоке аргона; затем образцы обрабатывали в потоке водорода в течение 20 мин, т.е. суммарное время, проведённое образцом в печи, составляло 70 мин. После этого реактор вынимали из печи и охлаждали до температуры $20^{\circ} \mathrm{C}$ в потоке аргона. В результате получали 4.7-4.8 г пирофорного нанопорошка никеля. Средний диаметр наночастиц, рассчитанный по величине удельной поверхности порошка, составлял 67 нм. Удельную поверхность наночастиц $\mathrm{Ni}$, определяли методом БЭТ на приборе Sorbi-M с погрешностью не более 3\%.

Нанопорошки никеля после изготовления хранили в атмосфере аргона чистотой 99.99\% в плотно закрытом стеклянном бюксе. После изготовления порошки обладают пирофорными свойствами. Вскрытие сосудов с нанопорошком и все последующее операции прессования, взвешивания и измерения размеров образцов проводили в герметичном боксе, заполненном инертным газом (аргоном) и снабжённым весами, прессом, измерительными инструментами, пресс-формами и шлюзом для смены порошков и образцов (Рис. 1). Концентрацию кислорода в боксе контролировали анализатором кислорода АКПМ-1-02Г. При открытии сосудов с порошком и в процессе прессования образцов концентрация кислорода в боксе не превышала 0.1 об.\%. При такой концентрации кислорода нанопорошки оставались пирофорными. Из нанопорошка никеля прессованием в стальной матрице были получены цилиндрические компактные образцы диаметром 5, 7 и 10 мм, различной плотности $1.2 \div 3.6$ г/ $\mathrm{cm}^{3}$. После прессования, каждый образец или несколько образцов помещали в отдельный бюкс и извлекали из бокса через шлюз.

Исследование процессов разогрева, воспламенения и горения образцов проводили на воздухе. Образцы вынимали из бюкса и устанавливали вертикально на 


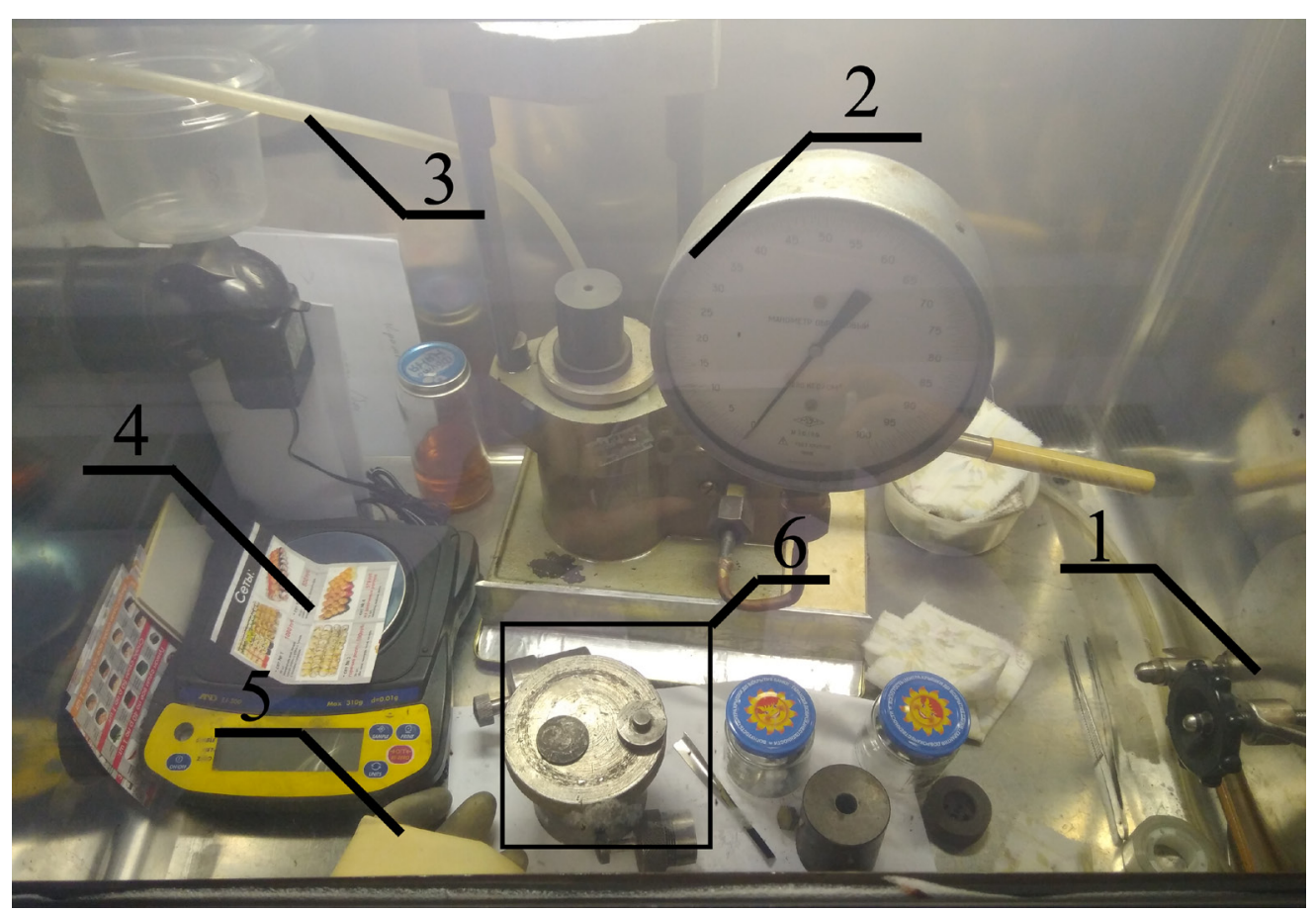

Pиc. 1. (Color online) Общий вид установки для получения компактных образцов внутри герметичного бокса: 1 - шлюз, 2 - пресс, 3 - выход на анализатор кислорода, 4 - цифровые весы, 5 - перчатки, 6 - набор пресс-форм.

Fig. 1. (Color online) General view of the device for obtaining compact samples inside the sealed box: $1-$ lock, $2-$ press, $3-$ oxygen analyzer output, 4 - digital scales, 5 - gloves, 6 - set of presses.

подставку из нитрида бора в течение 3 - 5 с. Изменение распределения температуры по поверхности образца во времени и определения максимальной температуры в каждый момент времени проводили инфракрасной камерой Flir 60 (60 кадров/c, $320 \times 240$ пикселей, интервал чувствительности 8-14 мкм). Фазовый состав образцов изучали с помощью дифрактометра ДРОН-3М с использованием монохроматического $\mathrm{Cu}_{\mathrm{K} \alpha}-$ излучения. Съемку дифрактограмм проводили в режиме шагового сканирования в интервале углов $2 \theta=20 \div 80^{\circ}$ с шагом съемки $0.2^{\circ}$. Полученные дифрактограммы анализировали с использованием базы данных PDF-2. Микроструктура поперечного излома цилиндрических образцов после самовоспламенения и горения исследовалась методом спектральной электронной микроскопии (СЭМ) на микроскопе Ultra Plus фирмы Carl Zeiss.

\section{3. Результаты и обсуждение}

Для проверки сохранения пирофорных свойств нанопорошка после манипуляций в перчаточном боксе часть порошка насыпалась в бюкс с притертой крышкой, который после извлечения из бокса открывали и высыпали порошок на воздухе. Порошок распылялся в воздухе, воспламенялся и горел, т.е. оставался пирофорным на протяжении всех подготовительных операций.

В первой, предварительной, серии экспериментов закрытые бюксы с образцами из пирофорного нанопорошка никеля после извлечения из бокса вплоть до начала эксперимента, т.е. до извлечения образцов из бюксов, находились в атмосфере аргона. В каждом бюксе находилось по одному компактному образцу. При такой постановке экспериментов после установки образцов на подложку, если их относительная плотность не превышала $0.2\left(\sim 1.8\right.$ г/ $\left.\mathrm{cm}^{3}\right)$ начинался интенсивный саморазогрев (до $\sim 550-600^{\circ} \mathrm{C}$ ), который фиксировался как термопарами, так и посредством тепловизионной съемки. При этом для плотностей 0.26-0.29 воспламенение образца могло происходить с задержкой в 10-15 с либо с меньшим значением максимальной температуры $\left(250^{\circ} \mathrm{C}\right)$. У образцов с плотностями выше 0.3 температура саморазогрева не превышала $80^{\circ} \mathrm{C}$.

Исходя из результатов первой серии экспериментов, в дальнейших исследованиях процесса пассивации компактных образцов из пирофорных нанопорошков никеля использовались образцы с относительной плотностью не более 0.2 .

В другой серии экспериментов образцы диаметром 5 мм из непассивированного нанопорошка никеля также прессовались в атмосфере аргона, однако после извлечения из бокса закрытые бюксы с образцами находились в воздушной атмосфере. Эксперименты показали, что режимы взаимодействия образцов с воздухом после извлечения их из бюксов зависели от длительности $t$ нахождения бюксов на воздухе. Так, первый образец ( $t$ меньше 15 мин) вел себя также как образцы из первой серии экспериментов. Т.е. происходил саморазогрев образцов, и они меняли свой цвет. Следующий образец, находящийся в бюксе на воздухе 15 мин после извлечения на воздух, разогревался до $80^{\circ} \mathrm{C}$ и не менял свой цвет. Образцы, 
находящиеся в бюксе на воздухе больше 20 мин, после извлечения из бюкса не разогревались выше $50^{\circ} \mathrm{C}$ и не меняли свой цвет. Следовательно, этого времени достаточно, чтобы произошла пассивация образцов.

Так как процесс пассивации связан с образованием защитной оксидной пленки на поверхности наночастиц, то он должен был сопровождаться увеличением веса образцов. Для проверки этой гипотезы бюксы с образцами после извлечения из емкости с аргоном устанавливали на аналитические весы GR-202 (погрешность измерений в диапазоне до 42 г - \pm 0.14 мг), которые фиксировали изменение массы образцов. Для корректного сравнения результатов экспериментов с образцами разного диаметра и выявления влияния удельной поверхности таких образцов (по сравнению с образцами диаметром 5 мм), на процесс пассивации их проводили следующим образом. В бюксы помещались по два или три компактных образца диаметром 5 мм. В этом случае их общая масса соответствовала образцам диаметром 7 и 10 мм. Также был один бюкс с пирофорным нанопорошком никеля насыпной плотности массой 0.56 г.

Все 5 мм образцы из бюксов, находившихся на воздухе 15-30 мин, оказались пассивированными и после установки на подложку самовоспламенение зафиксировано не было. Образец диаметром 10 мм и нанопорошок насыпной плотности также оказались пассированными (время нахождения на весах 30 мин). Образцы диаметром 7 мм, в свою очередь, остались пирофорными, но у них был зафиксирован наименьший привес за время выдержки бюкса на воздухе, который составил 0.14\% от массы компактных образцов. Результаты проведенных экспериментов, показали, что, если привес образцов при пассивации превышал $0.2 \%$ от массы компактных образцов, то у таких образцов и порошков после извлечения из бюксов самовоспламенение не происходило. Сохранение пирофорных свойств порошка проверялось путем его распыления на воздухе. Эксперименты показали, что разогрев порошка не наблюдался, что подтверждает его пассивацию. Сводные результаты измерений диаметра, веса, относительной плотности исходных образцов, и их привеса, температуры саморазогрева после пассивации, приведены в Табл. 1 .

Согласно данным [17] на 1 одном квадратном сантиметре поверхности адсорбируется (рассматривается хемосорбция) $10^{15}$ атомов кислорода, а массовая емкость 1.4 монослоя кислорода при полной хемосорбции равна
0.027 мкг $/ \mathrm{cm}^{2}$. В наших экспериментах при привесе образцов равном $0.22 \%$ увеличение массы образцов (три образца диаметром 5 мм в одном бюксе) составляло 2.6 мг. Удельная поверхность нанопорошков никеля, использованных в настоящей работе, по данным БЭТ, равна $10 \mathrm{~m}^{2} /$ г. Тогда на $1 \mathrm{~cm}^{2}$ поверхности образца адсорбировано 0.022 мкг кислорода, т.е. меньше одного монослоя. Естественно предположить, что не вся поверхность наночастиц является активной или равнодоступной, а хемосорбция происходит на части поверхности. Тогда, полученные данные по привесу образцов позволяют оценить какая часть поверхности образца является активной. Если предположить, что на активной части поверхности образца адсорбируется $N$ моноатомных слоев кислорода, то долю активной поверхности а можно рассчитать по формуле: $\alpha=0.022 /(N \times 0.027)$. Для $N$ равного $1,1.5,2$ доля активной поверхности составляет $0.81,0.54,0.41$ соответственно.

Для проверки гипотезы о том, что в процессе нахождения бюксов на воздухе произошла именно пассивация с сохранением химической активности, а не полное окисление образцов, были проведены следующие эксперименты. Образцы, которые после извлечения из бюкса не самовоспламенялись, поджигали с верхнего торца вольфрамовой спиралью (см. Рис. 2). Этот локальный разогрев приводил к распространению по образцу волны горения. Т.к. в процессе окисления поверхность образца меняла свой цвет, то скорость горения определяли с помощью покадровой обработки данных видеосъёмки. Как видно из Рис. 2, от верхнего

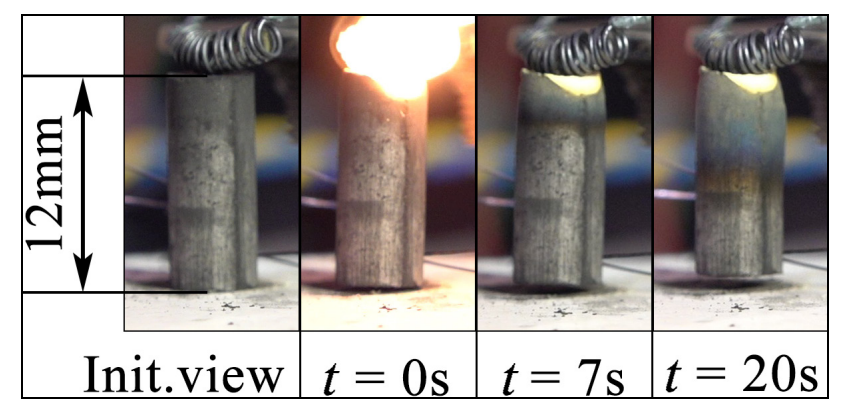

Pис. 2. (Color online) Покадровая съемка поджига и горения пассивированного образца диаметром 5 мм.

Fig. 2. (Color online) Frame-by-frame cinematography of ignition and combustion of passivated sample $5 \mathrm{~mm}$ in diameter.

Табл. 1. Сводные результаты измерений.

Table 1. Measurement summary.

\begin{tabular}{|c|c|c|c|c|}
\hline $\begin{array}{c}\text { Диаметр } \\
\text { образцов, мм } \\
\begin{array}{c}\text { Samples } \\
\text { diameter, mm }\end{array}\end{array}$ & $\begin{array}{c}\text { Масса, г (количество } \\
\text { образцов в бюксе } \times \text { на их вес) } \\
\text { Weight, g (number of samples in } \\
\text { a bottle } \times \text { by their weight) }\end{array}$ & $\begin{array}{c}\text { Относительная } \\
\text { плотность образцов } \\
\text { Relative density of } \\
\text { samples }\end{array}$ & $\begin{array}{c}\text { Привес, \% от массы образцов } \\
\text { (время выдержки на воздухе) } \\
\text { Weight gain,\% of the mass of } \\
\text { samples (exposure time in air) }\end{array}$ & $\begin{array}{c}\text { Температура } \\
\text { саморазогрева, }{ }^{\circ} \mathrm{C} \\
\text { Self-heating } \\
\text { temperature, }{ }^{\circ} \mathrm{C}\end{array}$ \\
\hline 5 & $2 \times 0.4$ & $0.19 ; 0.19$ & $0(0 \mathrm{mин} / \mathrm{min})$ & 600 \\
\hline 5 & $3 \times 0.4$ & $0.19 ; 0.19 ; 0.18$ & $0.22(30 \mathrm{Mин} / \mathrm{min})$ & 50 \\
\hline 5 & $2 \times 0.4$ & $0.19 ; 0.19$ & $0.2(15 \mathrm{mин} / \mathrm{min})$ & 80 \\
\hline 7 & $2 \times 0.7$ & $0.16 ; 0.15$ & $0.14(30 \mathrm{Mин} / \mathrm{min})$ & 570 \\
\hline Порошок / Powder & 1.6 & 0.13 & $0.23(30 \mathrm{мин} / \mathrm{min})$ & - \\
\hline
\end{tabular}


торца образца распространяется вниз волна горения приблизительно с постоянной скоростью. Типичные значения скорости горения составляют $V \approx 0.03 \mathrm{~cm} / \mathrm{c}$.

Ранее аналогичные результаты были получены на засыпках из пассивированных нанопорошков никеля [11]. Оказалось, что локальный разогрев спиралью приводил к распространению по поверхности засыпки волны реакции. Качественное совпадение наших результатов с данными работы [11] является дополнительным доказательством того факта, что в процессе нахождения бюксов на воздухе произошла пассивация образца.

На Рис. 3 представлены данные рентгенофазового анализа (РФА) пассивированного и, для сравнения, сгоревшего образцов диаметром 5 мм. Дифрактограммы пассивированных образцов других диаметров аналогичны. Как видно из Рис. 3 для пассивированного образца наблюдается только фаза $\mathrm{Ni}$, что позволяет говорить именно о пассивации образцов, а не частичном сгорании.

СЭМ излома образцов диаметром 5 мм приведен на Рис. 4. Видно, что отсутствуют следы спекания, а наночастицы никеля сохранили свой размер.

Интегральный энерго-дисперсионный анализ (ЭДА), проведенный с поверхности поперечных изломов (микроскоп Ultra Plus фирмы Carl Zeiss) показал практически равномерное распределение кислорода по сечению всех пассивированных образцов (Табл. 2). Точки 1-9 Табл. 2 брались на радиусе образца (движение от центра к поверхности), а точки 10-12 - в приповерхностной области образца. Это позволяет сделать вывод об объемном характере пассивации компактных образцов из нанопорошка никеля. Среднеквадратичное отклонение $S=\sqrt{\left(\sum_{n}(x-\bar{x})^{2}\right) / n}$ для образца диаметром 5 мм, рассчитанное на основании данных Табл. 2, составляет величину 0.9 ат.\%, что гораздо меньше среднего содержания кислорода на поверхности излома.

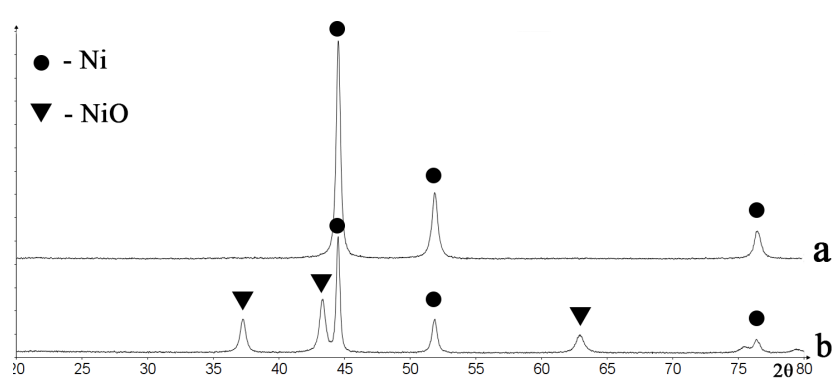

Рис. 3. Дифрактограммы пассивированных (а) и сгоревших (b) компактных образцов.

Fig. 3. X-ray patterns of passivated (a) and burnt (b) compact samples.

\section{4. Выводы}

Показано, что за время 20-30 мин нахождения на воздухе закрытых бюксов с притертой крышкой возможна пассивация компактных образцов из нанопорошка никеля.

Установлено, что привеса за счет реакции окисления в $0.2 \%$ от массы образца достаточно для пассивации компактных образцов различного диаметра с сохранением химической активности при инициировании реакции окисления высокотемпературным источником.

Анализ распределения кислорода по сечению пассивированных образцов позволяет говорить об объемном характере пассивации.

Оценена доля активной поверхности компактных образцов из пирофорного нанопорошка никеля.

Благодарности / Aknowledgements. Исследование выполнено за счет гранта Российского Научного Фонда (проект № 16-13-00013П). / This work was supported by the Russian Science Foundation (grant number 16-13-00013П).

Табл. 2. Содержание кислорода в различных областях излома пассивированного образца диаметром 5 мм, ат.\% по данным ЭДА. Table 2. Oxygen content at.\% in various fracture regions of a passivated sample $5 \mathrm{~mm}$ in diameter according to EDA.

\begin{tabular}{|c|c|c|c|c|c|c|c|c|c|c|c|}
\hline 1 & 2 & 3 & 4 & 5 & 6 & 7 & 8 & 9 & 10 & 11 & 12 \\
\hline 5.18 & 7.35 & 6.23 & 5.61 & 6.3 & 6.4 & 6.34 & 6.31 & 7.55 & 7.25 & 8.47 & 7.05 \\
\hline
\end{tabular}

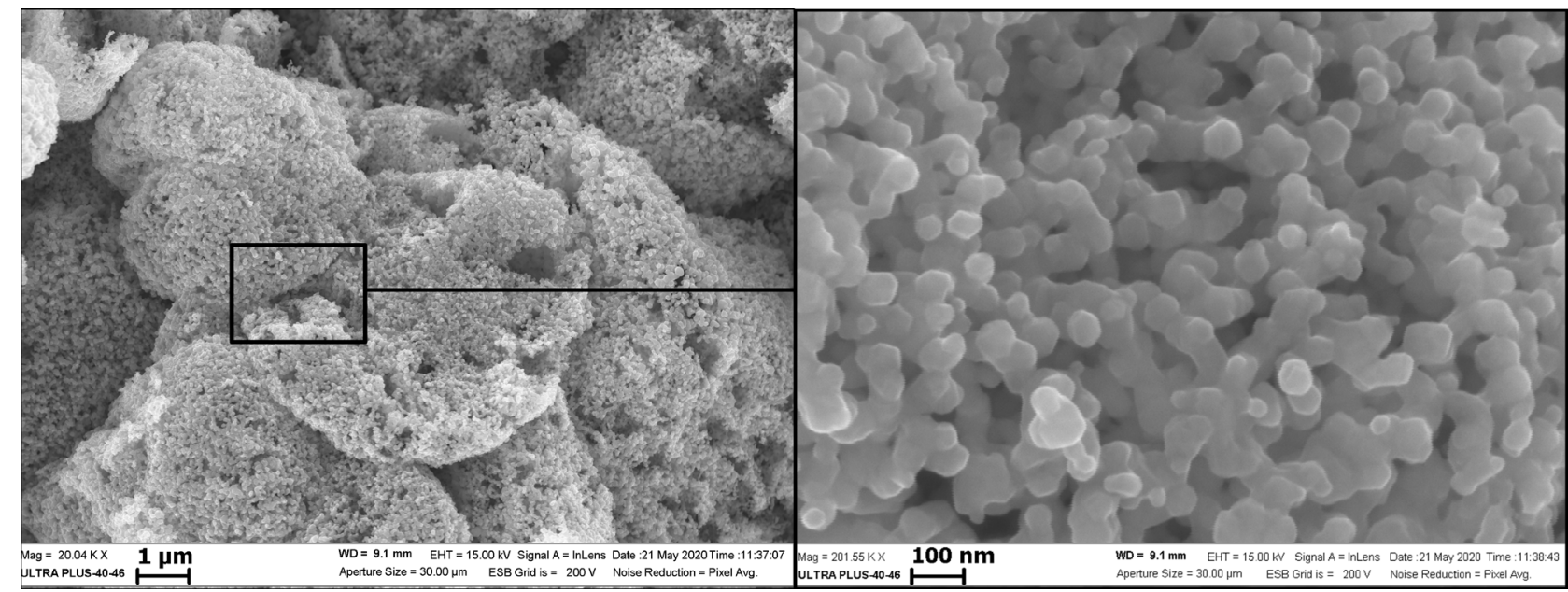

Рис. 4. СЭМ излома пассивированных компактных образцов диаметром 5 мм.

Fig. 4. SEM fracture of passivated compact samples $5 \mathrm{~mm}$ in diameter. 


\section{Литература/References}

1. J. Bouillard, A. Vignes, O. Dufaud, L. Perrin, D. Thomas. J. Hazard. Mater. 181, 873 (2010). Crossref

2. A. Pivkina, P. Ulyanova, Y. Frolov, S. Zavyalov, J. Schoonman. Propellants, Explosives, Pyrotechnics. 29, 39 (2004). Crossref

3. M. Hosokawa, K. Nogi, M. Naito, T. Yokoyama. Nanoparticle technology handbook. Elsevier (2007) 644p.

4. N. M. Rubtsov, B.S. Seplyarskii, M.I. Alymov. Ignition and wave processes in combustion of solids. Springer international publishing (2017) 284p. Crossref

5. M. Flannery, T.G. Desai, T. Matsoukas, S. Lotfizadeh, M. A. Oehlschlaeger. Hindawi Publishing Corporation Journal of Nanomaterials. 2015, 185 (2008). Crossref

6. M.J. Meziani, C.E. Bunker, F. Lu, H. Li, W. Wang, E.A. Guliants, R.A. Quinn, Y.-P.Sun. ACS Applied Materials \& Interfaces. 1, 703 (2009).

7. R. Nagarajan, T. A. Hatton. Nanoparticles: Synthesis, Stabilization, Passivation, and Functionalization. ACS Symposium Series. American Chemical Society, Washington, DC (2008). Crossref

8. M.I. Alymov, N.M. Rubtsov, B.S. Seplyarskii, V.A. Zelensky, A.B. Ankudinov, I.D. Kovalev,
R.A. Kochetkov, A.S. Shchukin, E.V. Petrov, N.A. Kochetov. Doklady chemistry. 484, 19 (2019). Crossref

9. M.I. Alymov, N.M. Rubtsov, B.S. Seplyarskii, R.A. Kochetkov, V.A. Zelensky, A.B. Ankudinov. Mendeleev Communications. 27, 631 (2017). Crossref

10. M.I. Alymov, N.M. Rubtsov, B.S. Seplyarskii, V.A. Zelensky, A. B. Ankudinov. Mendeleev Commun. 27, 482 (2017). Crossref

11. B.S. Seplyarskii, T.P. Ivleva, M.I. Alymov. Doklady chemistry. 478, 23 (2018). Crossref

12. S. Dong, H. Cheng, H. Yang, P. Hou, G.Zou. J. Phys.: Condensed Matter. 14, 11023 (2002). Crossref

13. E. M. Hunt, M. L. Pantoya. J. Applied Physics. 98, 034909 (2005). Crossref

14. F. Saceleanu, M. Idir, N. Chaumeix, J.Z. Wen. Front. Chem. 6, 465 (2018). Crossref

15. A. A. Gromov, U. Teipel. Metal Nanopowders: Production, Characterization, and Energetic Applications. John Wiley \& Sons (2014) 417p. Crossref

16. J.G. Dean. Ind. Eng. Chem. Soc. 44, 985 (1952). Crossref

17. F.H. Ribeiro, R.A. DallaBetta, G. J. Guskey, M. Boudart. Chem. Mater. 3, 805 (1991). Crossref 